\title{
The theophylline-enoxacin interaction: II. Changes in the disposition of theophylline and its metabolites during intermittent administration of enoxacin
}

\begin{abstract}
The pharmacokinetics of theophylline and its three major metabolites, 3-methylxanthine, 1-methylurate, and 1,3-dimethylurate, were studied during intermittent administration of enoxacin. The addition of enoxacin $(400 \mathrm{mg}$, twice daily) to a theophylline dosing regimen $(150 \mathrm{mg}$, twice daily) resulted in an immediate fall in plasma theophylline metabolite concentrations. Mean steady-state theophylline concentration in plasma during the dosing interval increased from 3.17 to $8.23 \mu \mathrm{g} / \mathrm{ml}$. The mean 12 hour recovery of total theophylline metabolite decreased from 76.3 to $38.6 \mathrm{mg}$. After the discontinuation of enoxacin, but not theophylline, the plasma theophylline metabolite levels immediately increased to near or above the concentrations observed before enoxacin coadministration. Concurrently, theophylline concentrations decreased to levels equivalent to those observed before enoxacin coadministration. In general, the changes in plasma theophylline concentrations observed after the addition or discontinuation of enoxacin were complete within 3 days. (Clin Pharmacol Ther 1989;46:420-8.)
\end{abstract}

Mark C. Rogge, PhD, William R. Solomon, MD, Allen J. Sedman, MD, PhD, Peter G. Welling, PhD, Jeffrey R. Koup, PharmD, and John G. Wagner, PhD Rensselaer, N.Y., and Ann Arbor, Mich.

Enoxacin, an investigational anti-infective agent of the fluoroquinolone class, gained considerable attention as a result of its ability to alter the disposition of theophylline. Wijnands et al. ${ }^{1}$ reported that nausea and vomiting developed in 8 of 10 patients when enoxacin was added to their theophylline drug regimens. In a subsequent report, Wijnands et al. ${ }^{2}$ reported that when enoxacin was administered orally at 800 to 1200 $\mathrm{mg} /$ day, a 2.6 -fold increase in mean plasma theophylline concentrations occurred. Maesen et al. ${ }^{3}$ reported symptoms suggestive of theophylline toxicity in 12 of

From the Department of Drug Metabolism and Pharmacokinetics, Sterling Research Group, Rensselaer, the Department of Internal Medicine, School of Medicine, the College of Pharmacy, Department of Pharmacology, and the Upjohn Center for Clinical Pharmacology, University of Michigan, and Parke Davis Pharmaceutical Research Division, Warner Lambert Company, Ann Arbor.

Supported by Parke Davis Pharmaceutical Research Division, Warner Lambert Company.

Received for publication Jan. 16, 1989; accepted May 29, 1989.

Reprint requests: John Wagner, $\mathrm{PhD}$, Upjohn Center for Clinical Pharmacology, UJ-3705/0504, University of Michigan Medical Center, Ann Arbor, MI 48109.

13/1/14289
15 patients taking enoxacin and theophylline concurrently. The enoxacin-theophylline interaction continues to generate interest as the character of this phenomenon unfolds in the literature. ${ }^{4.5}$

In our previous report ${ }^{6}$ the interaction of theophylline and enoxacin as a function of enoxacin dose was described. That article described enoxacininduced changes in the disposition of theophylline and its primary metabolites, 3-methylxanthine (3-MX), 1-methylurate (1-MU), and 1,3-dimethylurate (1,3$M U)$. It was shown that enoxacin administration reduced theophylline plasma clearance in a dosedependent fashion. Dose-dependent changes in the formation of theophylline metabolites were also observed.

This study was designed to determine the time course of changes in the disposition of theophylline and its metabolites during intermittent administration of enoxacin. Sustained-release theophylline (as a precaution against excessively high theophylline levels) was administered twice daily to subjects for 13 days. During the course of theophylline administration, enoxacin was added to the regimen for 5 days. With this intermittent dosing regimen, near-steady-state plasma theophylline and metabolite concentrations were achieved at three different times: before, during, and after enoxacin coad- 
ministration. Extensive sampling of blood and urine was conducted. This article describes the shifts that were observed in plasma concentrations and in urinary excretion of theophylline and three metabolites throughout the course of the study.

\section{METHODS}

Study design. The study had an eight-subject sequential design. Subjects were given $150 \mathrm{mg}$ theophylline (one half of a $300 \mathrm{mg}$ Theo-Dur tablet) orally every 12 hours ( $8 \mathrm{AM}$ and $8 \mathrm{PM}$ ) for 12 days ( 288 hours). On day 5 (96 hours), each subject began taking 400 mg enoxacin, as a single film-coated tablet, with each theophylline dose. Enoxacin continued to be administered through the morning dose of theophylline on day 9 (192 hours), at which time enoxacin administration was discontinued.

Blood samples were drawn into heparinized vacutainers from each subject at the following times (time zero corresponds to just before the first dose of theophylline): $0,60,72,73,74,76,78,80,82,84,96$, $108,120,132,144,156,168,180,192,193,194$, $196,198,200,202,204,216,228,240,252,264$, $276,288,289,290,292,294,296,298,300,312$, $324,336,348$, and 360 hours. Plasma was immediately separated from each sample, quick frozen, and stored at $-20^{\circ} \mathrm{C}$ until assayed. Blood sampling was particularly extensive on day 4 , just before enoxacin administration was begun, on day 9 , after 4 complete days of enoxacin coadministration, and on day 13, 4 days after enoxacin administration had been stopped. Urine was collected during each of the following time intervals: 0 (control), 72 to 84,84 to 96,96 to 108,108 to 120,120 to 132,132 to 144,144 to 156,156 to 168 , 168 to 180,180 to 192,192 to 204,204 to 216,216 to 228,228 to 240,240 to 252,252 to 264,264 to 276,276 to 288,288 to 300,300 to 312,312 to 336 , and 336 to 360 hours. Urine volumes from each collection period were measured and recorded. A $10 \mathrm{ml}$ aliquot of each collection was immediately frozen and stored at $-20^{\circ} \mathrm{C}$ until assayed. All plasma and urine samples were assayed for parent drug and metabolites within 2 weeks.

Subjects who participated in the study were healthy, nonsmoking male volunteers; each had signed an informed consent form before participation in the study. Their ages ranged from 22 to 47 years (mean, 28.0 years); their weights ranged from 147 to 183 pounds (mean, 169 pounds). All subjects adhered to a strict xanthine-free diet beginning 3 days before the first theophylline dose and extending for 3 days after the last theophylline dose.

Assay analysis. HPLC assays for the quantitation of enoxacin, theophylline, and metabolites in plasma and urine were described in a previous publication. ${ }^{4}$ Each assay allowed the estimation of each compound's concentration over a broad range adequate for the conduct of this study.

Assay sensitivity and reproducibility. The lowest concentration on the plasma standard curves was 0.2 $\mu \mathrm{g} / \mathrm{ml}$ for theophylline and $0.02 \mu \mathrm{g} / \mathrm{ml}$ for each theophylline metabolite. The lowest concentration on the plasma standard curves was $0.50 \mu \mathrm{g} / \mathrm{ml}$ for enoxacin and $0.25 \mu \mathrm{g} / \mathrm{ml}$ for the enoxacin oxometabolite. Corresponding concentrations for urine were $1.0 \mu \mathrm{g} / \mathrm{ml}$ for theophylline and each theophylline metabolite, 5.0 $\mu \mathrm{g} / \mathrm{ml}$ for enoxacin, and $2.5 \mu \mathrm{g} / \mathrm{ml}$ for the enoxacin oxometabolite. These concentrations were considered to be the assay sensitivities, and all concentrations measured below these values were taken as zero.

Pharmacokinetic analysis. The onset of the interaction was measured as a function of rising plasma theophylline concentrations vs time. The plasma theophylline concentration vs time data were fitted to the empiric first-order function:

$$
C_{t}=C_{0} \exp ^{(-k \cdot t)}+C_{s s}\left(1-\exp ^{(-k \cdot t)}\right)
$$

in which $C_{t}$ is the estimated plasma concentration at time $t, \mathrm{C}_{0}$ is the initial plasma concentration (mean of 84- and 96-hour minimum steady-state drug concentration in plasma $\left[\mathrm{C}_{\min }^{\mathrm{sS}}\right]$ values for onset and 192- and 204hour $\left[\mathrm{C}_{\min }^{\mathrm{SS}}\right]$ values for offset), $\mathrm{C}_{\mathrm{Ss}}$ is an estimated parameter equal to the new steady-state plasma concentration being approached, and $\mathrm{k}$ is the first-order rate constant that describes the rate of approach to the new steady state. The concentration-time data pairs were fitted by unweighted nonlinear least-squares regression analysis on PCNONLIN.?

An approximate time required for theophylline to reach $80 \%$ of steady-state plasma concentrations with multiple dosing was calculated as follows:

$$
\mathrm{T}_{80}=(2.32)(0.693 / \mathrm{k})
$$

in which $\mathrm{k}$ is the rate constant defined in equation 1 .

First-order terminal elimination rate constants $\left(\mathrm{k}_{\mathrm{e}}\right)$ were estimated by unweighted nonlinear least-squares regression of the log-linear plasma concentration-time data. The plasma elimination half-life $\left(t_{t_{12}}\right)$ was determined by dividing $\mathrm{k}_{\mathrm{e}}$ into 0.693 . The AUC from 0 hours through $\tau$ (AUC ${ }_{0}^{12}$ ) was estimated with the trapezoidal rule. The total amount of theophylline metabolite recovered in urine (as theophylline equivalents) during each collection interval was calculated with the following equation:

Total metabolite $=(1.09)\left(\mathrm{amt}_{3-\mathrm{Mx}}\right)+$

$$
(0.990)\left(\mathrm{amt}_{1-\mathrm{MU}}\right)+(0.919)\left(\mathrm{amt}_{1,3-\mathrm{MU}}\right)
$$




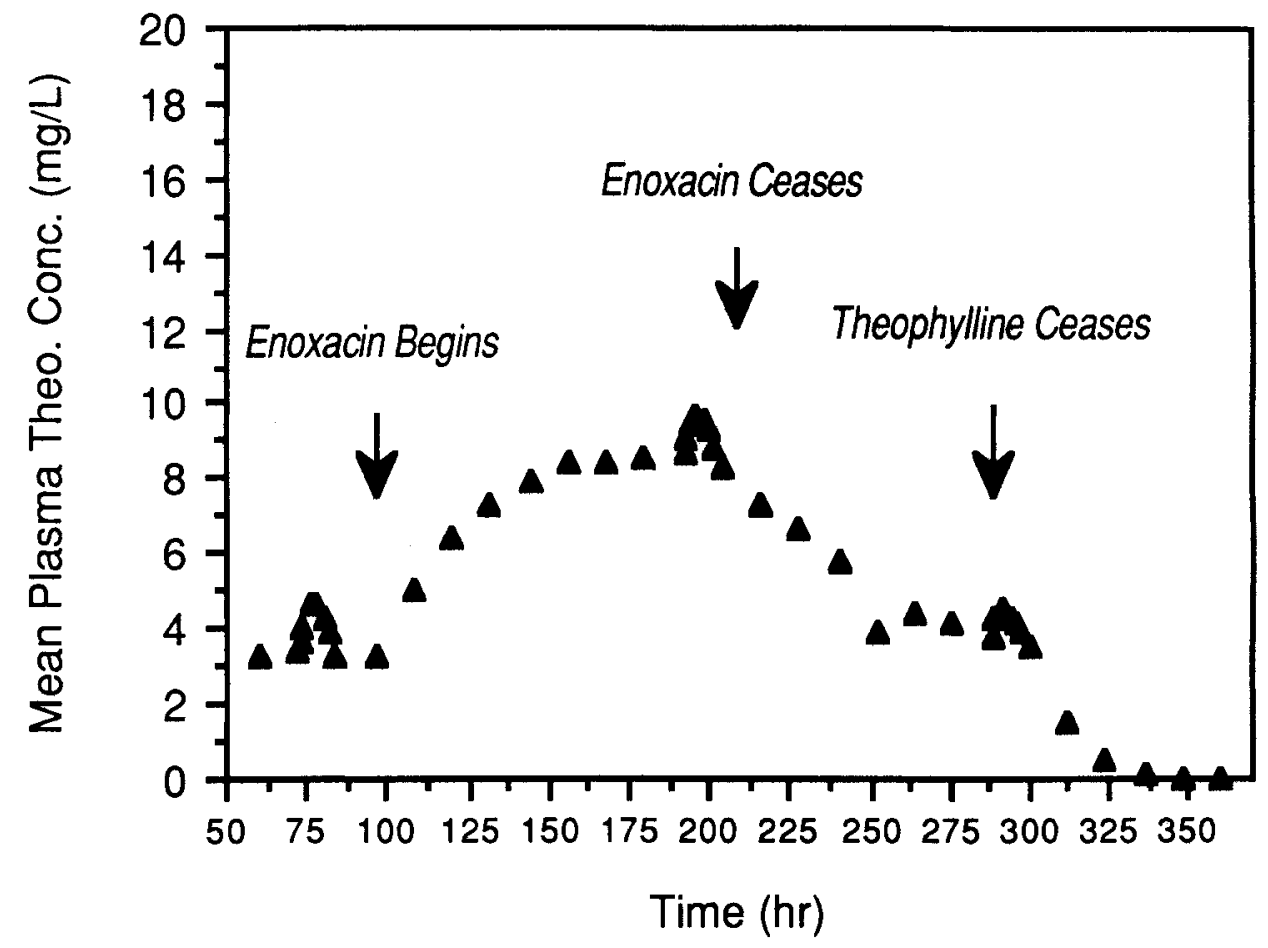

Fig. 1. Mean plasma theophylline concentration-time profile. The time period shown (60 to 360 hours) includes each of the three steady-state periods. Theophylline was administered as a TheoDur tablet, $150 \mathrm{mg}$, every 12 hours through 300 hours. Short-term rises in plasma theophylline concentrations ( 72 to 84,192 to 204 , and 288 to 300 hours) occurred during periods of frequent blood sampling after theophylline administration.

in which $\mathrm{MW}_{\text {Theo }} / \mathrm{MW}_{3-\mathrm{Mx}}=1.09, \mathrm{MW}_{\text {Theo }} / \mathrm{MW}_{1-\mathrm{MU}}=$ 0.990 , and $\mathrm{MW}_{\text {Theo }} / \mathrm{MW}_{1,3-\mathrm{MU}}=0.919$.

Renal clearances $\left(\mathrm{CL}_{\mathrm{R}}\right)$ were estimated by division of the amount of compound recovered in urine during each 12-hour time period by the compound's respective plasma AUC during the same time period.

Statistical analysis. All statistical analyses were conducted on an IBM 3090-400 mainframe computer (IBM Corp., Danbury, Conn.). The software system SAS (version 5.15) was used. General linear model procedures were used to conduct the ANOVAs; Scheffe's method of contrasting parameter values was followed. The Scheffe method $(\alpha=0.05)$ was used in lieu of the Tukey and Bonferroni methods because testing of multiple contrasts was conducted.

\section{RESULTS}

Assay reproducibility. Least-squares regression analysis was conducted on the plasma and urine assay validation data for theophylline and its three metabolites. For plasma calibration curve standards, mean coefficients of variation ranged from $2.38 \%$ to $4.04 \%$ for theophylline, $1.14 \%$ to $7.44 \%$ for $3-\mathrm{MX}, 2.14 \%$ to $3.98 \%$ for $1-\mathrm{MU}$, and $1.79 \%$ to $5.36 \%$ for $1,3-\mathrm{MU}$. For urine, mean coefficients of variation ranged from $1.01 \%$ to $1.77 \%$ for theophylline, $1.74 \%$ to $7.25 \%$ for $3-\mathrm{MX}, 5.35 \%$ to $9.87 \%$ for $1-\mathrm{MU}$, and $2.75 \%$ to $9.32 \%$ for 1,3-MU.

In the enoxacin and enoxacin oxometabolite plasma assay, the mean coefficients of variation from analysis of calibration curve data ranged from $2.10 \%$ to $4.04 \%$ and from $3.31 \%$ to $7.82 \%$, respectively. In the enoxacin and enoxacin oxometabolite urine assay, the mean coefficients of variation ranged from $3.05 \%$ to $7.59 \%$ and from $3.20 \%$ to $5.74 \%$, respectively.

Coefficients of variation estimated from the assay of quality control standards at the same time were of the same magnitude as those listed above.

Theophylline and metabolites. Fig. 1 presents mean plasma theophylline concentrations versus time during the course of the study. Table I contains mean $\mathrm{C}_{\max }^{\mathrm{ss}}$, $\mathrm{C}_{\min }^{\mathrm{ss}}$, and $\mathrm{t}_{\max }$ values of theophylline at steady state for each treatment phase. The initial mean theophylline steady-state parameters, $C_{\min }^{s s}, C_{\max }^{s s}$, and $t_{\max }$, ob- 
Table I. Steady-state pharmacokinetic parameters of theophylline before, during, and after enoxacin administration

\begin{tabular}{|c|c|c|c|c|c|c|c|c|c|}
\hline \multirow[b]{2}{*}{ Subject } & \multicolumn{3}{|c|}{ Before } & \multicolumn{3}{|c|}{ During } & \multicolumn{3}{|c|}{ After } \\
\hline & $C_{\min }^{S S}(\mu g / m l)$ & $C_{\max }^{s S}(\mu g / m l)$ & $t_{\max }(h r)$ & $C_{\min }^{S S}(\mu g / m l)$ & $C_{\max }^{s s}(\mu g / m l)$ & $t_{\max }(h r)$ & $C_{\min }^{S S}(\mu g / m l)$ & $C_{\max }^{s s}(\mu g / m l)$ & $t_{\max }(h r)$ \\
\hline 1 & 2.55 & 5.24 & 4.0 & 8.97 & 10.1 & 6.0 & 3.75 & 5.10 & 6.0 \\
\hline 2 & 1.91 & 3.56 & 4.0 & 6.48 & 8.12 & 8.0 & 3.25 & 4.09 & 2.0 \\
\hline 3 & 3.10 & 4.11 & 4.0 & 8.66 & 9.67 & 4.0 & 3.77 & 5.88 & 4.0 \\
\hline 4 & 2.32 & 3.07 & 8.0 & 7.05 & 8.43 & 2.0 & 3.01 & 4.55 & 4.0 \\
\hline 5 & 3.76 & 4.35 & 4.0 & 9.75 & 11.9 & 4.0 & 3.33 & 4.38 & 2.0 \\
\hline 6 & 5.20 & 8.23 & 4.0 & 8.74 & 10.8 & $0^{*}$ & 4.07 & 5.99 & 1.0 \\
\hline 7 & 4.35 & 6.00 & 6.0 & 8.74 & 10.7 & 2.0 & 3.58 & 4.69 & 6.0 \\
\hline 8 & 2.19 & 3.74 & 4.0 & 7.42 & 10.2 & 4.0 & 2.71 & 3.72 & 8.0 \\
\hline Mean & 3.17 & 4.79 & 4.8 & $8.23 \dagger$ & $9.99 \dagger$ & 3.8 & 3.43 & 4.80 & 4.1 \\
\hline $\mathrm{SD}$ & 1.17 & 1.68 & 1.5 & 1.11 & 1.25 & 2.5 & 0.44 & 0.81 & 2.4 \\
\hline
\end{tabular}

${ }^{*} \mathrm{C}_{\max }$ occurred just before administration of theophylline.

†Significantly higher than before and after values, which are not significantly different from one another $(p<0.05)$.

Table II. Parameter values associated with apparent first-order increase and subsequent decreases in plasma theophylline concentrations*

\begin{tabular}{|c|c|c|c|c|c|c|}
\hline \multirow[b]{2}{*}{ Subject } & \multicolumn{2}{|c|}{$\begin{array}{c}\text { Commencement of } \\
\text { enoxacin }\end{array}$} & \multicolumn{2}{|c|}{$\begin{array}{l}\text { Discontinuation of } \\
\text { enoxacin }\end{array}$} & \multicolumn{2}{|c|}{$\begin{array}{c}\text { Discontinuation of } \\
\text { theophylline }\end{array}$} \\
\hline & $k\left(h r^{-1}\right)$ & $r^{2}$ & $k\left(h r^{-1}\right)$ & $r^{2}$ & $k\left(h r^{-1}\right)$ & $r^{2}$ \\
\hline 1 & 0.043 & 0.878 & 0.015 & 0.933 & 0.076 & 0.992 \\
\hline 2 & 0.037 & 0.901 & 0.027 & 0.736 & 0.105 & 0.961 \\
\hline 3 & 0.033 & 0.861 & 0.033 & 0.955 & 0.077 & 0.975 \\
\hline 4 & 0.032 & 0.897 & 0.014 & 0.953 & 0.080 & 0.966 \\
\hline 5 & 0.015 & 0.964 & 0.014 & 0.901 & 0.070 & 0.993 \\
\hline 6 & 0.017 & 0.722 & 0.021 & 0.801 & 0.076 & 1.00 \\
\hline 7 & 0.056 & 0.702 & 0.025 & 0.964 & 0.070 & 0.990 \\
\hline 8 & 0.051 & 0.927 & 0.046 & 0.929 & 0.074 & 0.997 \\
\hline Mean & 0.035 & & 0.024 & & 0.079 & \\
\hline SD & 0.015 & & 0.011 & & 0.011 & \\
\hline
\end{tabular}

*The three periods in which the regressions were conducted were when enoxacin administration commenced, when enoxacin administration was discontinued, and when theophylline was discontinued.

tained during the 72 - to 84 -hour time period were 3.17 $\mu \mathrm{g} / \mathrm{ml}, 4.79 \mu \mathrm{g} / \mathrm{ml}$, and 4.8 hours, respectively. Four days after commencement of enoxacin coadministration (192 to 204 hours into the study), the mean parameter values at the new theophylline steady state were 8.23 $\mu \mathrm{g} / \mathrm{ml}, 9.99 \mu \mathrm{g} / \mathrm{ml}$, and 3.8 hours, respectively.

Theophylline $\mathrm{C}_{\min }^{\mathrm{sS}}$ values were determined to be at steady state through ANOVA of the plasma concentration data. Steady state was assumed when the concentration difference between two consecutive time points was not found to be significantly different. By this method of analysis, a new theophylline steady state was achieved within 48 hours of commencement of enoxacin administration and within 72 hours of discontinuance of enoxacin administration.
Theophylline $\mathrm{C}_{\min }^{\mathrm{ss}}$ values between the 72 - to 84 hour and 192- to 204-hour time periods were significantly different. Similarly, there was a statistically significant difference between the respective $\mathrm{C}_{\max }^{\mathrm{SS}}$ values. There were no significant differences between the $t_{\max }$ values.

The rise in plasma theophylline concentrations appeared to be described adequately by a first-order process (Fig. 1). Therefore $C_{\min }^{\text {ss }}$ values from the 84- to 204-hour time interval were fitted to equation 1 . Table II contains the relevant regression parameters. Coefficients of determination $\left(r^{2}\right)$ ranged from 0.702 to 0.964 for the individual data. The first-order onset rate constants ranged from 0.0150 to $0.0559 \mathrm{hr}^{-1}$, with a mean of $0.0354 \mathrm{hr}^{-1}$. The function intercept, or theoretic new 


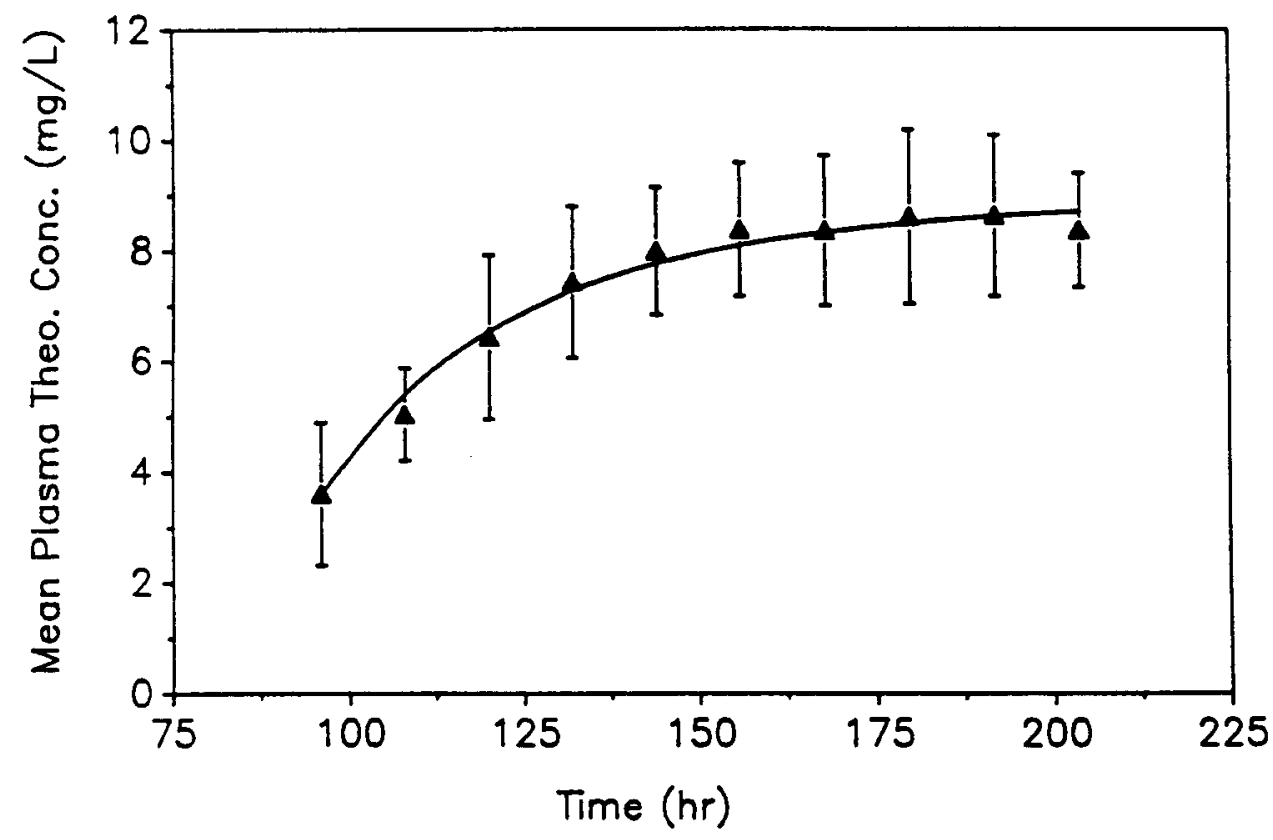

Fig. 2. Mean observed plasma theophylline concentration profile during onset of interaction. Mean predicted plasma concentrations overlay the observed values.

Table III. Plasma AUCs for theophylline and its major metabolites before ( 72 to 84 hours), during (192 to 204 hours), and after (288 to 300 hours) enoxacin administration

\begin{tabular}{|c|c|c|c|c|c|c|c|c|c|c|c|c|}
\hline \multirow[b]{2}{*}{ Subject } & \multicolumn{3}{|c|}{ Theophylline } & \multicolumn{3}{|c|}{$3-M X$} & \multicolumn{3}{|c|}{$1-M U$} & \multicolumn{3}{|c|}{$1,3-M U$} \\
\hline & $B$ & $D$ & $A$ & $B$ & $D$ & $A$ & $B$ & $D$ & $A$ & $B$ & $D$ & $A$ \\
\hline 1 & 53.8 & 114 & 55.6 & 1.19 & 0.085 & 2.03 & 0.405 & 0.426 & 0.930 & 1.47 & 0.349 & 2.55 \\
\hline 2 & 33.6 & 89.0 & 44.5 & 1.55 & 0 & 0.391 & 0.318 & 0.224 & 0.655 & 0.977 & 0.417 & 1.92 \\
\hline 3 & 44.9 & 113 & 59.2 & 0.170 & 0.175 & 3.03 & 0.811 & 0.586 & 1.14 & 2.46 & 3.52 & 3.11 \\
\hline 4 & 33.6 & 94.2 & 45.9 & 0.271 & 0 & 0.304 & 0.580 & 0.354 & 0.744 & 1.27 & 2.86 & 2.33 \\
\hline 5 & 48.8 & 133 & 46.0 & 1.09 & 0 & 0.172 & 1.89 & 0.689 & 2.13 & 4.22 & 2.21 & 3.61 \\
\hline 6 & 84.0 & 118 & 61.8 & 0.687 & 0 & 1.29 & 1.41 & 0.738 & 1.43 & 3.43 & 0.530 & 3.51 \\
\hline 7 & 60.1 & 118 & 49.1 & 0.813 & 0 & 0.848 & 1.60 & 0 & 1.50 & 2.98 & 2.29 & 2.08 \\
\hline 8 & 38.1 & 106 & 38.7 & 0.930 & 0.091 & 1.02 & 1.63 & 0.100 & 1.44 & 3.58 & 2.19 & 2.61 \\
\hline Mean & 49.6 & $111^{*}$ & 50.1 & 0.836 & $0.044 \dagger$ & 1.14 & 1.08 & $0.389 \dagger$ & 1.25 & 2.55 & $1.80 \ddagger$ & 2.72 \\
\hline SD & 16.8 & 14.1 & 7.99 & 0.461 & 0.066 & 0.977 & 0.621 & 0.271 & 0.483 & 1.20 & 1.21 & 0.634 \\
\hline
\end{tabular}

B, Before enoxacin administration; D, during enoxacin administration; A, after enoxacin administration.

*Significantly higher than before and after values, which are not significantly different from one another $(p<0.05)$

$†$ Significantly lower than before and after values, which are not significantly different from one another $(p<0.05)$.

$\ddagger$ No significant difference between before, during, and after values.

steady-state plasma concentration, was $9.04 \mu \mathrm{g} / \mathrm{ml}$. The observed time to achieve a new steady-state plasma theophylline concentration was between 48 and 60 hours. The harmonic mean (SD) of the theoretic time required to achieve $80 \%$ of the new steady-state concentration was 45.4 (18.8) hours. Fig. 2 presents mean observed and predicted plasma theophylline concentrations versus time after commencement of enoxacin coadministration.
Mean 12-hour plasma theophylline AUC values were 49.6 and $111 \mu \mathrm{g} \cdot \mathrm{hr} / \mathrm{ml}$ before and during enoxacin coadministration, respectively (Table III). The difference between these values was statistically significant. The mean 12-hour AUC values before enoxacin coadministration were $0.836,1.08$, and $2.55 \mu \mathrm{g} \cdot \mathrm{hr} / \mathrm{ml}$ for 3-MX, 1-MU, and 1,3-MU, respectively. The mean 12-hour AUC values during enoxacin coadministration were $0.044,0.389$, and $1.80 \mu \mathrm{g} \cdot \mathrm{hr} / \mathrm{ml}$ for $3-\mathrm{MX}$, 
Table IV. Steady-state plasma concentrations of the major metabolites of theophylline before, during, and after enoxacin administration

\begin{tabular}{|c|c|c|c|c|c|c|c|c|c|}
\hline \multirow[b]{3}{*}{ Subject } & \multicolumn{9}{|c|}{$C_{\min }^{\mathrm{SS}}$ plasma concentration $(\mu \mathrm{g} / \mathrm{ml})$} \\
\hline & \multicolumn{3}{|c|}{$3-M X$} & \multicolumn{3}{|c|}{$1-M U$} & \multicolumn{3}{|c|}{$1,3-M U$} \\
\hline & $B$ & $D$ & $A$ & $B$ & $D$ & $A$ & $B$ & $D$ & $A$ \\
\hline 1 & 0.085 & 0.011 & 0.232 & 0.045 & 0.024 & 0.086 & 0.133 & 0.018 & 0.021 \\
\hline 2 & 0.045 & 0.010 & 0.053 & 0.019 & 0.037 & 0.057 & 0.081 & 0.030 & 0.152 \\
\hline 3 & 0.053 & 0.019 & 0.166 & 0.090 & 0.038 & 0.068 & 0.186 & 0.273 & 0.187 \\
\hline 4 & 0.043 & 0 & 0.197 & 0.045 & 0.042 & 0.064 & 0.084 & 0.247 & 0.160 \\
\hline 5 & 0.054 & 0 & 0.012 & 0.150 & 0.023 & 0.151 & 0.378 & 0.158 & 0.247 \\
\hline 6 & 0.052 & 0 & 0.125 & 0.092 & 0.039 & 0.139 & 0.228 & 0.046 & 0.272 \\
\hline 7 & 0.058 & 0 & 0.066 & 0.099 & 0 & 0.106 & 0.232 & 0.132 & 0.163 \\
\hline 8 & 0.068 & 0 & 0.099 & 0.123 & 0 & 0.111 & 0.221 & 0.176 & 0.190 \\
\hline Mean & 0.057 & 0.005 & $0.119^{*}$ & 0.083 & $0.025 \dagger$ & 0.098 & 0.193 & $0.135 \ddagger$ & 0.197 \\
\hline SD & 0.013 & 0.007 & 0.076 & 0.044 & 0.017 & 0.035 & 0.097 & 0.097 & 0.043 \\
\hline
\end{tabular}

B, Before enoxacin administration; D, during enoxacin administration; A, after enoxacin administration.

*Significantly higher than before and during values, which are not significantly different from one another $(p<0.05)$.

+ Significantly lower than before and after values, which are not significantly different from one another $(p<0.05)$

‡No significant differences between before, during, and after values.

Table $\mathbf{V}$. The amounts of each theophylline metabolite excreted in the urine at steady state before enoxacin coadministration (72 to 84 hours) and during enoxacin coadministration (192 to 204 hours)

\begin{tabular}{|c|c|c|c|c|c|c|c|c|c|}
\hline \multirow[b]{2}{*}{ Subject } & \multicolumn{4}{|c|}{ Before } & \multicolumn{4}{|c|}{ During } & \multirow[b]{2}{*}{$\begin{array}{c}\text { Ratio of total } \\
\text { metabolites } \\
\text { during/before }\end{array}$} \\
\hline & $3-M X$ & $1-M U$ & $1,3-M U$ & $\begin{array}{c}\text { Total metabolite } \\
\text { theophylline } \\
\text { equivalents }\end{array}$ & $3-M X$ & $1-M U$ & $1,3-M U$ & $\begin{array}{c}\text { Total metabolite } \\
\text { theophylline } \\
\text { equivalents }\end{array}$ & \\
\hline 1 & 3.53 & 7.74 & 34.2 & 42.9 & 0.929 & 4.16 & 5.68 & 10.3 & 0.240 \\
\hline 2 & 7.09 & 22.0 & 24.1 & 51.6 & 1.41 & 3.43 & 24.5 & 27.4 & 0.531 \\
\hline 3 & 2.98 & 4.61 & 14.1 & 20.7 & 1.09 & 1.46 & 14.9 & 16.3 & 0.787 \\
\hline 4 & 4.98 & 8.40 & 20.8 & 32.9 & 2.14 & 1.63 & 22.1 & 24.2 & 0.736 \\
\hline 5 & 14.9 & 34.8 & 52.1 & 98.5 & 14.6 & 10.9 & 29.4 & 53.6 & 0.544 \\
\hline 6 & 17.8 & 26.5 & 78.0 & 117 & 7.07 & 9.74 & 7.70 & 24.4 & 0.209 \\
\hline 7 & 13.5 & 23.5 & 61.5 & 94.4 & 6.48 & 16.1 & 56.8 & 75.1 & 0.796 \\
\hline 8 & 19.1 & 44.6 & 95.2 & 152 & 6.17 & 18.6 & 57.0 & 77.5 & 0.510 \\
\hline Mean & $10.5^{*}$ & $21.5^{*}$ & $47.5^{*}$ & $76.3^{*}$ & 4.99 & 8.25 & 27.3 & 38.6 & \\
\hline SD & 6.58 & 14.1 & 29.2 & 46.1 & 4.67 & 6.63 & 20.0 & 26.5 & \\
\hline
\end{tabular}

*Significantly different from the corresponding amount during enoxacin coadministration $(p<0.05)$.

1-MU, and 1,3-MU, respectively. The 12-hour AUC values for 3-MX and 1-MU were significantly lower during enoxacin coadministration than before enoxacin coadministration.

Table IV contains mean steady-state $\mathrm{C}_{\min }^{\mathrm{SS}}$ values for each metabolite before, during, and after enoxacin coadministration. Mean steady-state $\mathrm{C}_{\min }^{\text {ss }}$ values of 3-MX, 1-MU, and 1,3-MU before enoxacin coadministration were $0.057,0.083$, and $0.193 \mu \mathrm{g} / \mathrm{ml}$, respectively. During enoxacin coadministration, these concentrations decreased to $0.005,0.025$, and 0.135 $\mu \mathrm{g} / \mathrm{ml}$, respectively. Between these study periods, there were statistically significant differences in the
$\mathrm{C}_{\min }^{\mathrm{sS}}$ values for both 3-MX and 1-MU but not for 1,3MU. In two subjects (Nos. 3 and 4) the plasma 1,3MU concentration increased after commencement of enoxacin coadministration.

Table $\mathrm{V}$ contains the mean amount of each theophylline metabolite recovered in the urine during the 72to 84-hour and 192- to 204-hour time periods. The mean amounts of 3-MX, 1-MU, and 1,3-MU recovered before and during enoxacin coadministration were 10.5 and $4.99 \mathrm{mg}, 21.5$ and $8.25 \mathrm{mg}$, and 47.5 and $27.3 \mathrm{mg}$, respectively. The mean (SD) ratio of total metabolite recovered during enoxacin coadministration $(38.6 \mathrm{mg})$ to total metabolite recovered before enoxacin 


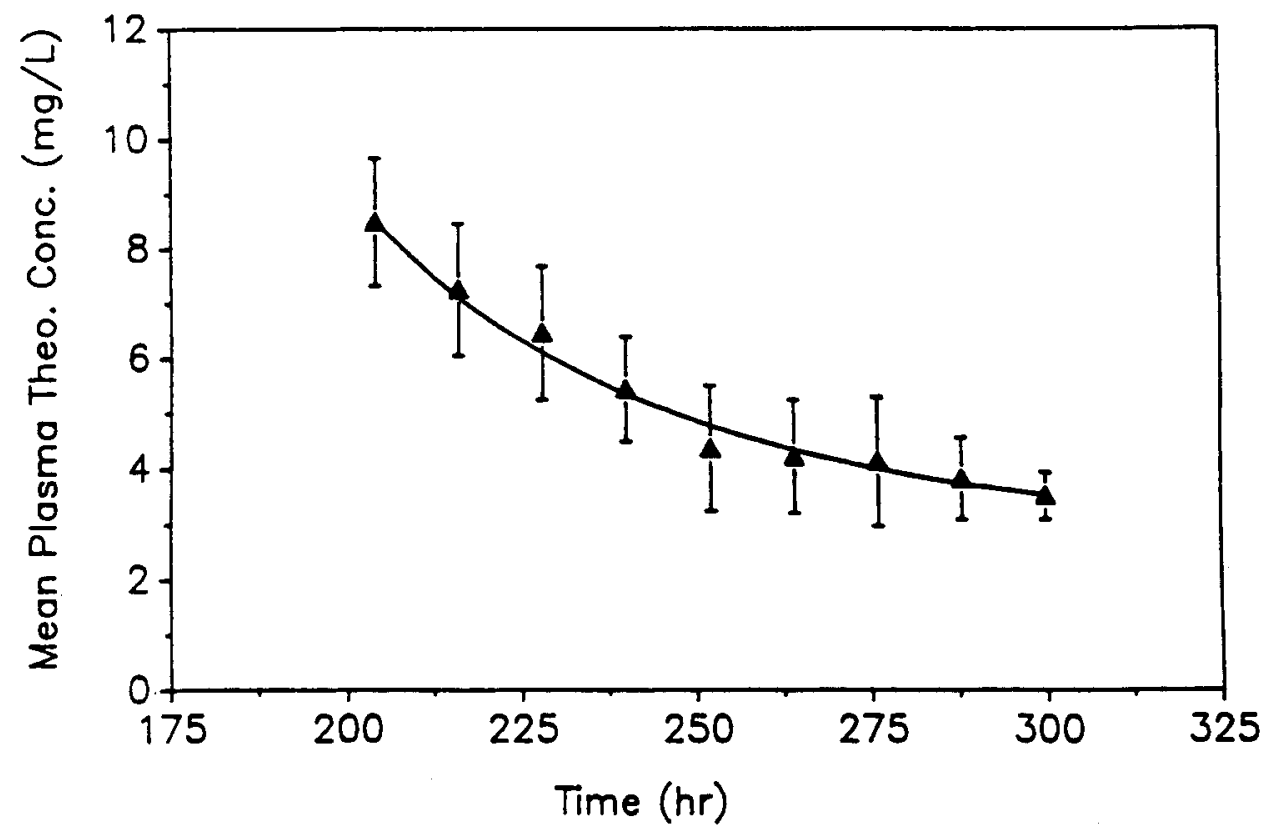

Fig. 3. Mean observed plasma theophylline concentration profile during offset of interaction. Mean predicted plasma concentrations overlay the observed values.

coadministration $(76.3 \mathrm{mg})$ was $0.544(0.228)$, with a range of 0.209 to 0.796 .

After enoxacin was discontinued, plasma theophylline concentrations decreased, with a mean first-order rate constant of $0.0244 \mathrm{hr}^{-1}$ (Table II). The coefficients of determination for the eight regressions ranged from 0.736 to 0.964 . The harmonic mean (SD) of the theoretic time required to achieve $80 \%$ of steady state was 65.9 (32.5) hours. ANOVA of $\mathrm{C}_{\min }^{\text {ss }}$ values indicated that steady state had been achieved between 60 and 72 hours. Fig. 3 presents mean observed and predicted plasma theophylline concentrations versus time. During the 288- to 300-hour sampling period, mean steadystate theophylline $\mathrm{C}_{\min }^{\mathrm{ss}}, \mathrm{C}_{\max }^{\mathrm{ss}}$, and $t_{\max }$ values were $3.43 \mu \mathrm{g} / \mathrm{ml}, 4.78 \mu \mathrm{g} / \mathrm{ml}$, and 4.1 hours, respectively. The steady-state theophylline $\mathrm{C}_{\min }^{\mathrm{SS}}$ and $\mathrm{C}_{\max }^{\mathrm{SS}}$ values after enoxacin had been discontinued were each significantly less than during enoxacin coadministration. There were no statistically significant differences in theophylline $\mathrm{C}_{\min }^{\mathrm{Ss}}, \mathrm{C}_{\max }^{\mathrm{sS}}$, or $\mathrm{t}_{\max }$ values between the periods before enoxacin coadministration and after enoxacin coadministration.

Table II also contains the regression parameters of the fall in plasma theophylline concentrations after theophylline was discontinued. The mean $\mathrm{k}_{\mathrm{e}}$ was estimated to be 0.079 and the coefficients of determination of the regressions ranged from 0.961 to 1.00 . The harmonic theophylline elimination $t_{1 / 2}$ was 8.83 hours.

Mean steady-state $\mathrm{C}_{\min }^{\mathrm{sS}}$ values for 3-MX, 1-MU, and
1,3-MU after discontinuation of enoxacin were 0.119 , 0.0978 , and $0.197 \mu \mathrm{g} / \mathrm{ml}$, respectively. Steady-state $\mathrm{C}_{\min }^{\text {sS }}$ plasma concentrations of 3-MX after discontinuation of enoxacin were significantly greater than steady-state 3-MX $\mathrm{C}_{\min }^{\mathrm{ss}}$ values both before and during enoxacin coadministration. Plasma 1-MU concentrations were significantly lower during enoxacin coadministration than after enoxacin coadministration. Plasma 1,3-MU concentrations during enoxacin coadministration were not significantly different from those after enoxacin was discontinued.

After enoxacin was discontinued, the mean steadystate 12-hour plasma AUC values for 3-MX, 1-MU, and $1,3-\mathrm{MU}$ were $1.14,1.25$, and $2.72 \mu \mathrm{g} \cdot \mathrm{hr} / \mathrm{ml}$, respectively. The plasma AUC values for 3-MX and 1-MU were significantly greater than their respective values during enoxacin coadministration but not different from those determined before enoxacin coadministration.

Enoxacin and oxometabolite. Fig. 4 presents mean plasma enoxacin concentrations versus time during the course of the study. After approximately 36 hours of twice-daily oral administration, plasma enoxacin concentrations were at steady state, yielding a mean $\mathrm{C}_{\min }^{\text {SS }}$ value of $0.88 \mu \mathrm{g} / \mathrm{ml}$. At the 216 -hour sampling time, 12 hours after the last enoxacin dose, plasma enoxacin concentrations were below the minimum quantifiable level in all subjects.

In general, plasma concentrations of the enoxacin 


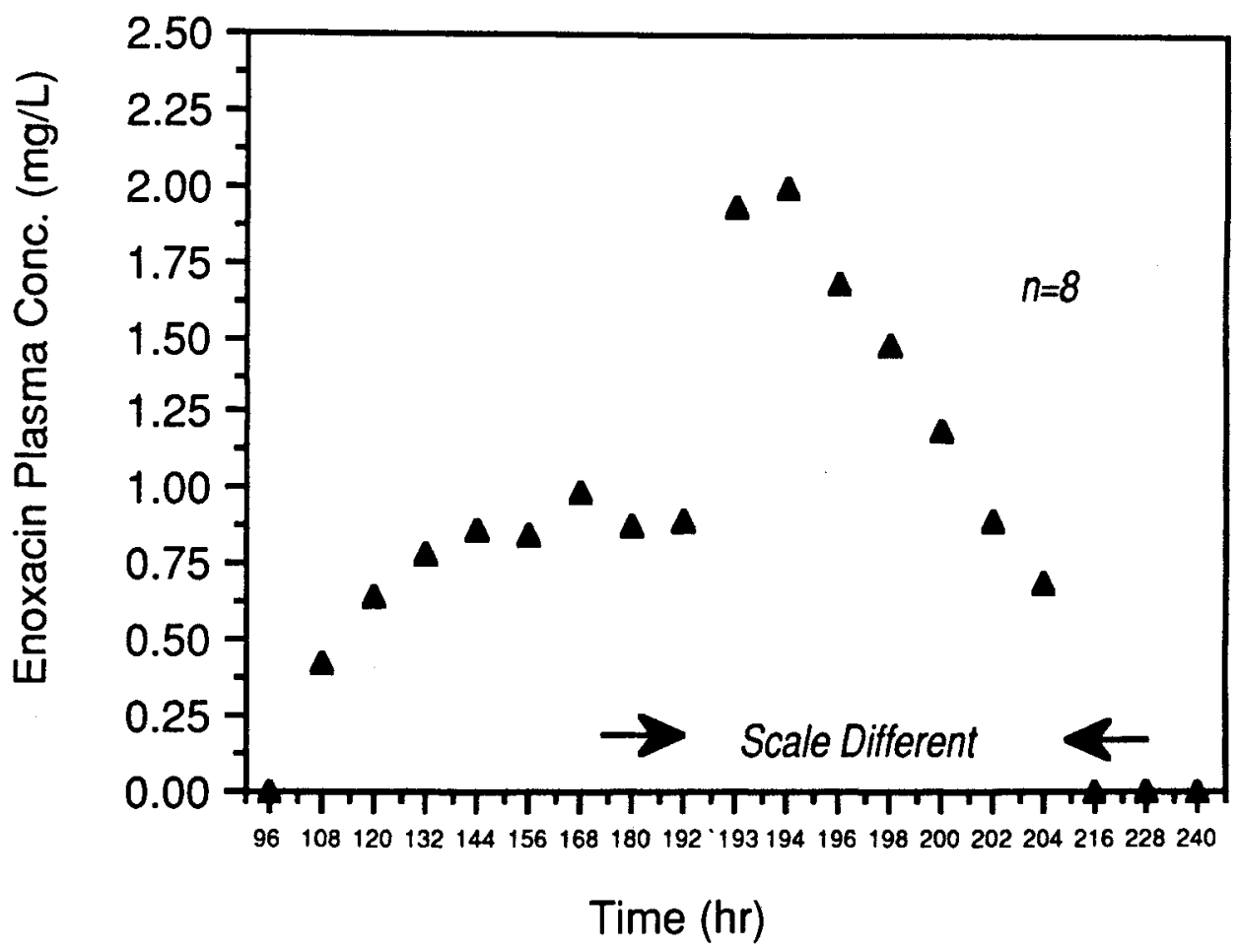

Fig. 4. Mean plasma enoxacin concentration-time profile. Enoxacin administration began at 96 hours and was discontinued at 204 hours. Enoxacin tablets ( $400 \mathrm{mg}$ ) were administered with each theophylline dose. Blood samples were collected frequently between 192 hours and 204 hours, resulting in the apparent rise in plasma enoxacin concentrations.

oxometabolite were below the minimum detectable level. Only between 180 and 204 hours were mean plasma concentrations greater than zero. The mean (SD) 12-hour plasma enoxacin oxometabolite concentrations were $0.0313(0.0884), 0.0419(0.118)$, and 0.0374 $(0.106) \mu \mathrm{g} / \mathrm{ml}$ at 180,192 , and 204 hours, respectively. The low plasma concentrations of enoxacin oxometabolite precluded further pharmacokinetic analysis.

No significant differences in theophylline or theophylline metabolite $C_{R}$ were detected among the three steady-state theophylline phases.

\section{DISCUSSION}

This study was designed to characterize plasma concentrations of theophylline and its metabolites during intermittent enoxacin administration. The results indicate that plasma concentration profiles of theophylline and its metabolites changed substantially when enoxacin was added to the drug regimen.

In enoxacin-naive subjects, plasma theophylline concentrations were at steady-state levels by 60 hours into the theophylline dosing schedule (Fig. 1). After enoxacin coadministration was begun, an immediate rise in plasma theophylline concentrations occurred. The mean estimated new steady-state plasma theophylline concentration, $9.04 \mu \mathrm{g} / \mathrm{ml}$, was very close to the observed mean value of $8.53 \mu \mathrm{g} / \mathrm{ml}$.

Assuming that the rise in plasma theophylline concentrations occurred by an apparent first-order process, a new steady-state plasma concentration would have been reached within approximately 45 hours after commencement of enoxacin coadministration. This is similar to the observed time of approximately 48 hours.

When enoxacin was added to the theophylline regimen, a dramatic fall in plasma theophylline metabolite concentrations was observed. The mean steady-state

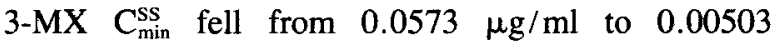
$\mu \mathrm{g} / \mathrm{ml}$, and the mean steady-state $1-\mathrm{MU} \mathrm{C}_{\min }^{\mathrm{ss}}$ fell from $0.0829 \mu \mathrm{g} / \mathrm{ml}$ to $0.0252 \mu \mathrm{g} / \mathrm{ml}$.

The mean steady-state $1,3-\mathrm{MU} \mathrm{C}_{\text {min }}^{\mathrm{SS}}$, which appeared to be least affected by enoxacin coadministration in this study, fell from $0.193 \mu \mathrm{g} / \mathrm{ml}$ to $0.135 \mu \mathrm{g} / \mathrm{ml}$. However, in two subjects, plasma concentrations of 1,3-MU rose when enoxacin coadministration was begun. It is plausible that, in some subjects, the 1,3-MU pathway is less sensitive to enoxacin-induced inhibition than in other subjects. 
Like the steady-state $\mathrm{C}_{\min }^{\mathrm{ss}}$ values for theophylline and each of its metabolites, the steady-state 12-hour AUC values shifted with enoxacin coadministration. The mean theophylline AUC more than doubled from $49.6 \mu \mathrm{g} \cdot \mathrm{hr} / \mathrm{ml}$ to $111 \mu \mathrm{g} \cdot \mathrm{hr} / \mathrm{ml}$; the increase was statistically significant. Conversely, AUC values for each theophylline metabolite fell; the 3-MX and 1-MU values fell significantly.

The fall in plasma theophylline metabolite concentrations coincided with a substantial fall in urinary recovery of theophylline metabolites. Mean ratios of 3-MX, 1-MU, and 1,3-MU recovered in urine ("during/before" enoxacin coadministration) at the steadystate time periods were $0.475,0.384$, and 0.575 , respectively. Individual recovery values translated into a mean total theophylline metabolite ratio of 0.544 . Hence the overall formation of theophylline major metabolites was suppressed by approximately $50 \%$ when twice-daily $400 \mathrm{mg}$ doses of enoxacin were administered with $150 \mathrm{mg}$ theophylline.

When enoxacin administration was discontinued, plasma theophylline concentrations immediately began to fall to new steady-state levels. Plasma theophylline concentrations approached new steady-state levels within 3 days after discontinuation of enoxacin administration. The predicted time to reach $80 \%$ of the new steady-state concentration (65.9 hours) agrees reasonably well with the fall in observed plasma theophylline concentrations. The new steady-state concentrations were statistically indistinguishable from the steady-state concentrations before enoxacin administration.

Theophylline metabolite concentrations responded immediately to the discontinuation of enoxacin administration. Plasma concentrations of each metabolite began to rise within 12 hours after the last enoxacin dose. After enoxacin administration was discontinued and plasma theophylline concentrations had reached a new steady state, $1-\mathrm{MU}$ and $1,3-\mathrm{MU} \mathrm{C}_{\min }^{\mathrm{ss}}$ values were similar to values obtained before enoxacin administration.

Our previous study ${ }^{6}$ indicated that the degree of suppression of theophylline metabolism was dependent on the dose of enoxacin given. The present study showed that the time course for both the onset and the offset of the interaction is rapid. New steady-state theophylline and metabolite plasma concentrations are achieved within approximately 3 days of starting and stopping enoxacin dosage. Thus any untoward increase in plasma theophylline concentrations during enoxacin administration is readily manageable by reducing the theophylline dosage.

\section{References}

1. Wijnands WJA, Van Herwaarden CLA, Vree TB. Enoxacin raises plasma theophylline concentrations. Lancet 1984;2:108-9.

2. Wijnands WJA, Van Herwaarden CLA, Vree TB. Enoxacin decreases the clearance of theophylline in man. $\mathrm{Br} \mathrm{J}$ Clin Pharmacol 1985;20:583-8.

3. Maesen FPV, Teengs JP, Baur C, Davies BI. Enoxacin raises plasma theophylline levels. Lancet 1984;2:530.

4. Takagi K, Hasegawa T, Yamaki K, Suzuki R, Watanabe $T$, Satake T. Interaction between theophylline and enoxacin. Int J Clin Pharmacol Ther Toxicol 1988;26:288-92.

5. Takagi K, Hasegawa T, Ogura Y, et al. Comparative studies on interaction between theophylline and quinolones. Int J Clin Pharmacol Ther Toxicol 1988;26:288-92.

6. Rogge MC, Solomon WR, Sedman AJ, Welling PG, Toothaker RD, Wagner JG. The theophylline-enoxacin interaction: I. Effect of dose size on theophylline disposition. Clin Pharmacol Ther 1988;44:579-87.

7. PCNONLIN, version V02. Lexington, Kentucky: Statistical Consultants. 1986. 